\title{
Current indications for elective surgical treatment of dilated ascending aorta: A new formula
}

Riccardo Codecasa, MD, Massimo A. Mariani, MD, PhD, Alessandro D'Alfonso, MD, Carmela Nardi, MD, and Jan G. Grandjean, MD, PhD, Pisa, Italy

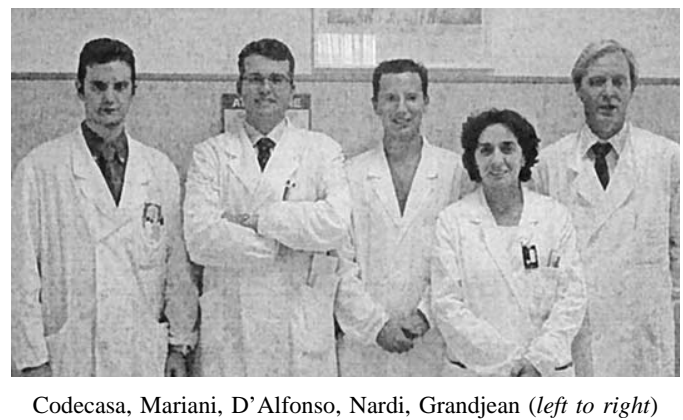

$\mathrm{T}$ he question as to when is the right time to operate on a dilated ascending aorta has not yet been definitively answered. In cases of rupture or a Stanford type A dissection, operative intervention provides the only chance for the patient to survive. In cases of increased aortic size, the indication for surgery or follow-up needs a standardized process that takes into account all available patient data. Currently, however, there is not complete agreement as to which criteria to use to solve this problem. By calculating the right time for elective surgery, when the operative risk is lower than the risk of dilationrelated complications, it could be ideally possible to avoid urgent surgical procedures on the ascending aorta. For this reason, a simple and quick method to determine the correct operative timing on the basis of clinical and echocardiographic findings would be useful to the surgeon. Currently, the size of the aorta and the underlying aortic pathologic process ${ }^{1-3}$ are considered the most important factors in predicting complications. The aim of this study is to move from the current criteria of indication for aortic surgery (the mean cutoff diameter) to a standard method of indication for elective surgery with echocardiographic measurements and few simple data obtained from the individual patient's clinical history. To reach this goal, we reviewed the literature data in a synthesis and then developed a new formula.

\section{Methods}

To define the "normal" size of the aorta, we stratified the measures on the basis of sex and age. The chosen approach for visualization was 2-dimensional echocardiography, because it is the routine diagnostic imaging for the ascending aorta. The wide set of healthy individual data from Roman and colleagues ${ }^{4}$ was used, including data from 52 healthy infants and 135 healthy adults. Echocardiography was performed with the patient in the left decubitus

\footnotetext{
From the Department Cardio Thoracic Surgery, University of Pisa, Pisa, Italy.

Received for publication Feb 15, 2002; accepted for publication Oct 23, 2002.

Address for reprints: Massimo A Mariani, MD, PhD, Department of Cardio Thoracic Surgery, Ospedale Cisanello, Via Paradisa, 2, I-56122 Pisa, Italy.

J Thorac Cardiovasc Surg 2003;125:1528-30

Copyright $\odot 2003$ by The American Association for Thoracic Surgery $0022-5223 / 2003 \$ 30.00+0$

doi:10.1016/S0022-5223(03)00059-X
}

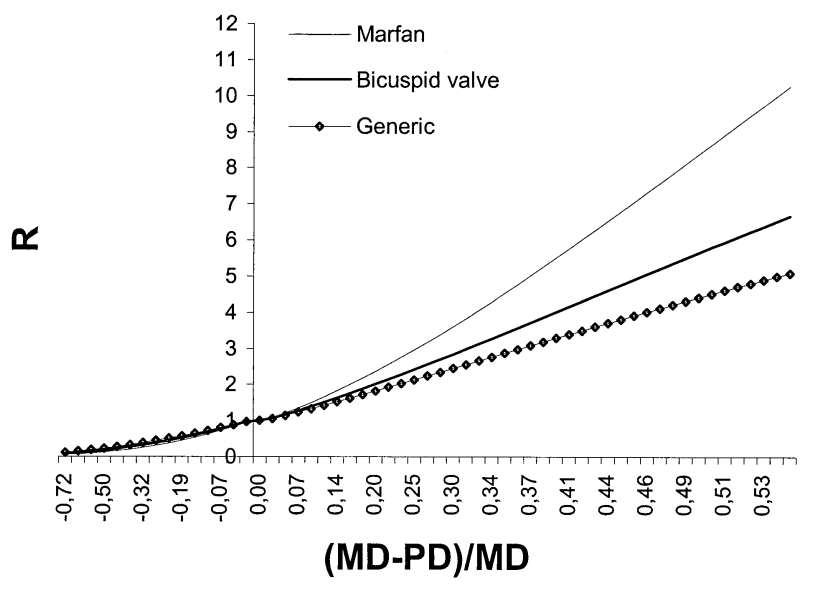

Figure 1. Calculated risks of complications in patients older than 40 years with $1.75 \mathrm{~m}^{2}$ BSA and Marfan, bicuspid aortic valve, and generic underlying pathologic conditions.

position, marking up to 6 cycles of the aortic root and left ventricle. ${ }^{4,5}$ In Roman and colleagues' series, ${ }^{4}$ sizes were obtained at four levels: annulus, sinuses of Valsalva, supra-aortic ridge, and proximal ascending aorta. For our study, we referred to the supraaortic ridge level. Measurements were made perpendicular to the long axis of the aorta with the leading-edge technique in views showing the largest aortic diameters. Approximate 95\% normal confidence intervals were derived as 2 SEs of the estimate for aortic root dimensions above and below the regression line of the variable with body size. In Roman and colleagues' population, ${ }^{4}$ these confidence intervals encompassed 350 of 359 data points (97\%), whereas only 2 of $359(0.6 \%)$ of values from healthy subjects fell above normal limits. Although gender, blood pressure, and stroke volume are significant correlates of aortic root dimensions, body size and age appear to be the primary independent determinants of aortic size in healthy people. Upper $95 \%$ normal confidence limits of aortic root diameters (expressed in centimeters) at the supra-aortic ridge (SR95\%) are presented in the following formulas:

1. Infants and children: SR95\% $=1.21+0.8 \times \mathrm{BSA}$.

2. Adults younger than 40 years: SR95\% $=1.48+0.82 \times$ BSA.

3. Adults older than 40 years: SR95\% $=2.35+0.62 \times$ BSA. SR95\% was considered, in the following steps, to represent the predicted diameter (PD); that is, the higher normal value for the 
TABLE 1. Features and results

\begin{tabular}{|c|c|c|c|c|c|c|}
\hline Patient & $\begin{array}{l}\text { MD } \\
(\mathrm{cm})\end{array}$ & $\begin{array}{l}\text { PD } \\
(\mathrm{cm})\end{array}$ & Risk & $\begin{array}{c}\text { Operation } \\
\text { (yes/no) }\end{array}$ & $\begin{array}{l}\text { Follow-up } \\
\text { (mo) }\end{array}$ & Complications* \\
\hline 1 & 5.5 & 3.7 & 2.73 & No & 3 & No \\
\hline 2 & 5.0 & 3.8 & 2.06 & No & 6 & No \\
\hline 3 & 6.0 & 3.6 & 3.27 & Not & 3 & No \\
\hline 4 & 5.0 & 3.4 & 3.80 & Yes & - & No \\
\hline 5 & 6.3 & 3.5 & 3.81 & Yes & - & No \\
\hline 6 & 7.0 & 3.4 & 4.65 & Yes & - & No \\
\hline 7 & 4.0 & 3.1 & 2.51 & No & 6 & No \\
\hline 8 & 4.5 & 3.6 & 1.82 & No & 12 & No \\
\hline 9 & 4.0 & 3.6 & 1.39 & No & 12 & No \\
\hline 10 & 4.1 & 3.5 & 1.89 & No & 12 & No \\
\hline 11 & 5.0 & 3.8 & 2.83 & No & 3 & No \\
\hline 12 & 4.6 & 3.5 & 2.8 & No & 3 & No \\
\hline 13 & 4.6 & 3.3 & 3.43 & Yes & - & No \\
\hline 14 & 4.3 & 3.4 & 2.00 & No & 12 & No \\
\hline 15 & 4.5 & 3.4 & 3.00 & Yes & - & No \\
\hline
\end{tabular}

*Complications as of September 30, 2001.

tThe patient refused surgery.

patient of a given age and body surface area (BSA). PD includes $95 \%$ of normal aortic size for a given BSA in a cluster of agestratified patients.

Once we had defined the PD, we searched for a mathematic relationship among it, the diameter measured by echocardiography, and the risk of rupture or Stanford type A dissection. Ergin and associates ${ }^{6}$ in the Aortic Surgery Symposium VI (Mount Sinai Medical Center, New York, 1998), dealing with timing of indication for elective surgical treatment of the dilated ascending aorta, noted the following: (1) Magnitude of the risk for spontaneous rupture or dissection is closely related to the aortic ratio (measured diameter MD/PD). (2) The cutoff aortic ratio varies according to the underlying pathologic process of the aortic wall. They suggested considering the risk the same for an aortic ratio of 1.3 in patients with Marfan syndrome (with familial history) and in patients with chronic dissection, for 1.4 in patients with bicuspid valve with dysfunction, and for 1.5 in patients with other conditions. Moreover, Legget and colleagues ${ }^{7}$ suggested that patients with aortic dimensions smaller than these values of aortic ratio could be observed at follow-up, delaying surgery. In addition, they showed that a ratio of 1.3 in Marfan syndrome increases the risk of complication by 2.7 , thus adding a quantitative measurement of the risk.

\section{Results}

On the basis of previous data, we traced an exponential curve with calculated risk of rupture or dissection $(\mathrm{R})$ on the $y$-axis and the ratio (MD - $\mathrm{PD}$ )/MD on the $\mathrm{x}$-axis. This ratio is positive in cases of increased aortic ratio, equal to 0 in cases of an aortic ratio of 1 $(\mathrm{PD}=\mathrm{MD}$ ), and negative in cases of MD lower than PD (Figure 1 ). When $M D$ is equal to $P D, R$ is 1 ; it rapidly increases on the right side of the curve (MD $>\mathrm{PD}$ ) and slowly decreases on the left side (MD $<\mathrm{PD}$ ). In this formula, we introduced a coefficient (C) to give the $R$ value an unique significance in the presence of different underlying pathologic processes. This coefficient was computed as the ratio $\mathrm{MD} /(\mathrm{MD}-\mathrm{PD})$, the inverse of (MD -
PD)/MD. Because critical aortic ratio (MD/PD) assumes different values according to Ergin and associates, ${ }^{6}$ for Marfan and chronic dissection $(\mathrm{MD} / \mathrm{PD}=1.3$ ) the value of $\mathrm{C}$ is 4.3 , for bicuspid aortic valve $(\mathrm{MD} / \mathrm{PD}=1.4) \mathrm{C}$ is 3.5 , and for other conditions $(\mathrm{MD} / \mathrm{PD}$ $=1.5$ ), $\mathrm{C}$ is 3.0. The following formula was defined:

$$
\mathrm{R}=\mathrm{e}^{\mathrm{C} \times[\mathrm{MD}-\mathrm{PD}] / \mathrm{MD}}
$$

where MD and PD are expressed in centimeters. We considered R greater than 2.7 as a potential indication for surgery. ${ }^{7}$ For a 50 -year-old patient with a BSA of $1.75 \mathrm{~m}^{2}$ and Marfan syndrome, an $\mathrm{R}$ of 2.7 would correspond to $4.5 \mathrm{~cm}$; in the case of generic risk, it would correspond to $5.2 \mathrm{~cm}$. We underscore that indication for surgery begins just above these values; however, as suggested by Ergin and associates, ${ }^{6}$ it should be taken into account to add as much as 0.15 to the aortic ratio, on the basis of the surgeon's experience, in indicating surgery for an otherwise symptom-free patient. That way we can quite safely consider the surgical option when $\mathrm{R}$ is greater than 3 . The operation should not be delayed if the aortic size is higher than the critical aortic size, expressed as the following:

$$
\text { Critical aortic size }=\mathrm{PD} \times \mathrm{K}
$$

where $\mathrm{K}$ is $1.45(1.3+0.15)$ in Marfan syndrome and chronic dissection, $1.55(1.4+0.15)$ in bicuspid aortic valve, and 1.65 (1.5 $+0.15)$ in other conditions.

It is possible to reverse the calculation for any given level of risk to determine what it means in terms of the size of the supra-aortic ridge (MD):

$$
\mathrm{MD}=\frac{\mathrm{C} \times \mathrm{PD}}{\mathrm{C}-\ln \mathrm{R}}
$$

where MD is the size of the supra-aortic ridge corresponding to the risk, $\mathrm{C}$ is the pathology-related coefficient, $\mathrm{PD}$ is the PD for the individual patient, and $\ln \mathrm{R}$ is the natural logarithm of the risk to evaluate. 


\section{Application}

On the basis of our formula, we prospectively studied the patients who were referred to our center for isolated dilation of the ascending aorta during a 6-month period (April through September 2001). Data from a total of 15 patients were collected, and the decision making was based mainly on $\mathrm{R}$ value. Six patients with $\mathrm{R}$ values of at least 3 were assigned to elective surgery, but 1 refused the operation, choosing to undergo a new control after 3 months. The other 9 patients were assigned to undergo echocardiographic follow-up: after 3 months for R between 2.7 and 3, after 6 months for $\mathrm{R}$ between 2.0 and 2.7, and after 12 months for $\mathrm{R}$ less than 2.0. None of the 15 patients had any complications (Table 1).

\section{Discussion}

Isolated dilation of ascending aorta requires particular care in identification of the critical size at which risk of rupture or dissection becomes greater then the risk of elective surgery. The surgeon's experience in aortic root surgery remains an important factor but cannot represent the only determinant in the statement of timing. At present, one of the most used criteria to evaluate a dilated ascending aorta is based on the rate of aneurysm dilatation. $^{1,6-11}$ This parameter, which describes the increase of the diameter of ascending aorta in serial assessment, is related to the chance of complications (an increase greater than 5\%/y in the aortic ratio in a patient with Marfan syndrome leads to an increase in the risk of complications by a factor of 4.1). ${ }^{6}$ However, the need for consecutive determinations makes this approach less than useful in estimation of immediate risk with a single measurement. For patients with aortic dilation at the first echocardiography, a "one time" prediction parameter should be available to help choose between surgery and follow-up. On the basis of the $\mathrm{R}$ value, we tried to estimate how often surveillance is necessary and when surgery might be needed. To make the application of these issues easier, a simple HTML page has been created; it includes a few fields to fill in (age, height, weight, comorbidity) and calculates the $\mathrm{PD}$, the calculated risk (R), and the critical aortic size. This page is available at www.aortaonline.org.

Although in a rational approach to the dilated ascending aorta we must underscore the importance of interindividual variations and the single institutional experience (making it difficult to create an absolute definition of risk), we believe that a personalized profile of risk is better than the traditional mean cutoff. We are using this formula now in our routine clinical setting, with encouraging results. To determine more quantitative criteria for these important issues, we suggest a prospective approach that uses our formula for the indication for elective surgery of the dilated ascending aorta in clinical practice, ideally collecting the data in a multicenter study.

\section{References}

1. Dapunt OE, Galla JD, Sadeghi AM, Lansman SL, Mezrow CK, de Asla RA, et al. The natural history of thoracic aortic aneurysms. J Thorac Cardiovascular Surg. 1994;107:1323-33.

2. Pachulski RT, Weinberg AL, Chan KL. Aortic aneurysm in patients with functionally normal or minimally stenotic bicuspid aortic valve. Am J Cardiol. 1991;67:781-2.

3. Huntington K, Hunter AG, Chan KL. A prospective study to assess the frequency of familial clustering of congenital bicuspid aortic valve. J Am Coll Cardiol. 1997;30:1809-12.

4. Roman MJ, Devereux RB, Kramer-Fox R, O’Loughlin J, Spitzer M, Robins J. Two-dimensional echocardiographic aortic root dimensions in normal children and adults. Am J Cardiol. 1989;64:507-12.

5. Sahn DJ, DeMaria A, Kisslo J, Weyman A. Recommendations regarding quantitation in M-mode echocardiography: results of a survey of echocardiographic measurements. Circulation. 1978;58:1072-83.

6. Ergin MA, Spielvogel D, Apaydin A, Lansman SL, McCullogh JN, Galla JD, et al. Surgical treatment of the dilated ascending aorta: when and how? Ann Thorac Surg.. 1999;67:1834-9.

7. Legget ME, Unger TA, O’Sullivan CK, Zwink TR, Bennett RL, Byers $\mathrm{PH}$, et al. Aortic root complications in Marfan's syndrome: identification of a lower risk group. Heart. 1996;75:389-95.

8. Coady MA, Rizzo JA, Hammond GL, Kopf GS, Elefteriades JA. Surgical intervention criteria for thoracic aortic aneurysms: a study of growth rates and complications. Ann Thorac Surg. 1999;67:1922-6.

9. Prenger K, Pieters I, Cheriex E. Aortic dissection after aortic valve replacement: incidence and consequences for strategy. J Card Surg. 1994;9:495-8

10. Shimada I, Rooney SJ, Pagano D, Farneti PA, Davies P, Guest PJ, et al. Prediction of thoracic aortic aneurysm expansion: validation of formulae describing growth. Ann Thorac Surg. 1999;67:1968-70.

11. Pitt M, Bonser R. Natural history of thoracic aneurysms: an overview. J Card Surg. 1997;12:270-8. 